\title{
Helicobacter pylori infection: relation with cardiovascular risk factors, ischaemic heart disease, and social class
}

Department of Epidemiology and Public Health, Queen's

University of Belfast,

Royal Group of

Hospitals, Belfast

A E Evans

E E McCrum

L J Murray

Department of

Microbiology and

Immunobiology,

Queen's University of

Belfast, Royal Group

of Hospitals, Belfast

K B Bamford

Department of Public

Health Medicine,

Eastern Health and

Social Services Board,

Belfast

D P J O'Reilly

Correspondence to:

Dr L J Murray, Department

of Social Medicine, Bristol

University, Canynge Hall,

Whiteladies Road, Bristol

BS8 2PR.

Accepted for publication

2 May 1995

Liam J Murray, Kathy B Bamford, Dermot P J O'Reilly, Evelyn E McCrum, Alun E Evans

\begin{abstract}
Objective-To determine whether Helicobacter pylori infection is associated with the development of ischaemic heart disease and whether such infection can explain the social class inequality in ischaemic heart disease.
\end{abstract}

Design-Cardiovascular risk factor levels, prevalence of ischaemic heart disease (Rose questionnaire angina, and/or a history of myocardial infarction), and serum antibodies to $H$ pylori (enzyme linked immunosorbent assay) were assessed in a cross sectional population based survey. Setting-Belfast and surrounding districts, Northern Ireland.

Participants-1182 men and 1198 women aged 25-64 years randomly selected from the Central Services Agency's general practitioner lists.

Main outcome measures-The relation of $H$ pylori infection with cardiovascular risk factors and ischaemic heart disease. The association of social class with ischaemic heart disease.

Results-Systolic and diastolic blood pressure, plasma viscosity, and total cholesterol were not associated with $H$ pylori infection. A weak negative association existed between $H$ pylori infection and fibrinogen (mean (SE) difference in fibrinogen between infected and uninfected individuals $-0.09(0.04) \mathrm{g} / \mathrm{l}, \mathrm{P}=$ $0.02)$ and between infection in women and high density lipoprotein (HDL) cholesterol (mean (SE) difference in HDL cholesterol between infected and uninfected individuals $-0.06(0.02) \mathrm{mmol} / \mathrm{h}, P$ $=0.006$ ). A potentially important association was demonstrated between $H$ pylori infection and ischaemic heart disease but this did not reach statistical significance (odds ratio ( $95 \%$ confidence interval (CI) $1.51(0.93$ to $2 \cdot 45), P=0 \cdot 1)$. Social class was associated with ischaemic heart disease independently of cardiovascular risk factors and $H$ pylori infection (odds ratio, manual $v$ non-manual $(95 \% \mathrm{CI}) 1.82(1.14$ to 2.91 ), $P=0.01$ ).

Conclusion-H pylori may be independently associated with the development of ischaemic heart disease but if this is so the mechanism by which this effect is exerted is not through increased concentration of plasma fibrinogen. $H$ pylori infection does not explain the social class inequality in ischaemic heart disease which exists independently of known cardiovascular risk factors.
(Br Heart f 1995;74:497-501)

Keywords: Helicobacter pylori infection; prevalence of ischaemic heart disease; social class and ischaemic heart disease; cardiovascular risk factors

There are substantial social class differences in the risk of developing ischaemic heart disease. ${ }^{12}$ Interclass variations in established cardiovascular risk factors such as cigarette smoking, raised blood pressure, and serum total cholesterol concentration account for a proportion of these differences but much of the association remains unexplained. ${ }^{3}$ This suggests that there are important unrecognised factors, influencing the development of ischaemic heart disease which are more prevalent in the lower social classes. Chronic infection of the gastric mucosa with Helicobacter pylori ( $H$ pylori), a curved, Gram negative bacillus, predominantly affects persons of low social class ${ }^{4-7}$ and infection with this organism has been shown to be associated with ischaemic heart disease. ${ }^{8}$ Furthermore, plasma fibrinogen, a risk factor for ischaemic heart disease, ${ }^{9}$ has recently been found to be increased in $H$ pylori infected patients ${ }^{10}$ and fibrinogen concentrations are raised in persons of lower social class, ${ }^{1112}$ irrespective of smoking habit. Infection with $H$ pylori is possibly an important determinant of the social class inequality in ischaemic heart disease and the increased risk of this condition in $H$ pylori infected individuals may, at least in part, be mediated through raised plasma fibrinogen.

We have studied the relations among $H$ pylori infection, social class, and ischaemic heart disease in 2380 randomly selected participants from a cross sectional population survey in an area with a high incidence of ischaemic heart disease. ${ }^{13}$ We have also examined the relations between $H$ pylori infection and established cardiovascular risk factors including fibrinogen.

\section{Patients and methods}

STUDY POPULATION

Participants studied were those recruited in Northern Ireland into the World Health Organisation co-ordinated MONICA (monitoring of trends and determinants in cardiovascular disease) Project's second population survey. A stratified random sample of 4912 participants aged 25-64 years was drawn from the Northern Ireland Central Services Agency's general practitioner lists. Some 745 of the sample were ineligible because they 
resided outside the MONICA Project area (Belfast and surrounding districts) or their age was outside the specified range: 30 were dead. A further 485 were untraceable after at least two visits to the last known address and reference to other sources. Of the 3652 eligible and traceable subjects, 2380 were screened by trained observers adhering to a strict protocol between September 1986 and July 1987 giving a response rate of $65 \cdot 2 \%$.

\section{SURVEY METHODS}

At screening information was collected on medical history, diet, alcohol consumption, smoking history, education, and socio economic status. The London School of Hygiene and Tropical Medicine chest pain questionnaire (the Rose questionnaire) was administered. Height, weight, and blood pressure (Hawksley random zero sphymomanometer; diastolic phase V) were measured and a blood sample taken: centrifugation and separation took place within $3 \mathrm{~h}$ of venepuncture.

Blood was analysed for total cholesterol by the CHOD-PAP method (Boehringner (CF) and Sohne, Mannheim), high density lipoprotein (HDL)-cholesterol by precipitation employing phosphotungstic magnesium reagents, ${ }^{14}$ plasma fibrinogen with the Clauss method, and plasma viscosity using the Coulter-Harkness capillary viscometer. ${ }^{15}$ Serum not required for these assays was divided into aliquots and stored at $-70^{\circ} \mathrm{C}$. Serum used for the determination of $H$ pylor status had thawed on only one previous occasion. Serum was available for detection of $H$ pylori antibody in 2115 participants (88.9\%) and plasma was available for estimation of fibrinogen concentration and viscosity in 2101 and 1899 individuals respectively.

\section{DETERMINATION OF H PYLORI STATUS}

$H$ pylori specific immunoglobulin G (IgG) antibodies were measured by enzyme linked immunosorbent assay using an acid glycine extract of $H$ pylori NCTC $12686 .{ }^{16}$ Sera were diluted 1:200 and assayed in duplicate and the mean optical density expressed as a percentage of the optical density of a positive control serum assayed on the same plate. The results obtained were bimodally distributed. A log normal distribution which closely approximated the first peak of the biomodal distribution was calculated and a threshold was determined which allocated $95 \%$ of the results in this peak as negative for $H$ pylori antibodies. The sensitivity and specificity of the system within a test population of 75 symptomatic patients undergoing endoscopy and antral biopsy compared with that of culture and polymerase chain reaction were $95 \%$ and $94 \%$ respectively.

\section{STATISTICAL METHODS}

Participants were classified as having ischaemic heart disease if they answered affirmatively to the question "have you ever been told by your doctor that you have had a heart attack, coronary thrombosis, or a myocardial infarct?" or if they reported a history of chest pain with characteristics satisfying all of the Rose angina questionnaire criteria: (1) the presence of any pain, discomfort, pressure, or heaviness; (2) located in the upper or middle sternum or the left anterior chest and left arm; (3) present when hurrying, walking uphill, or at an ordinary pace on the level; (4) that requires the patient to stop, slow down or take nitroglycerin; (5) with subsequent relief; (6) occurring in $10 \mathrm{~min}$ or less.

Age, body mass index, systolic and diastolic blood pressure, fibrinogen, plasma viscosity, total cholesterol and HDL-cholesterol were used in the analyses as continuous untransformed variables. Smoking habit was grouped into four categories: current smoker of 20 or more cigarettes a day, current smoker of less than 20 cigarettes a day, ex-smoker, and never smoked. The amount of exercise (recreational or occupational) taken in a week was categorised into three groups, none, less than $2 \mathrm{~h}$ and $2 \mathrm{~h}$ or more. Social class was coded according to the registrar general's classification of occupations and was grouped into manual (IIIM, IV, and V) and non-manual (I, II, and IIINM).

Bivariable (independent samples $t$ test and $\chi^{2}$ ) and multivariable analyses (multiple regression and logistic regression) were performed using SPSS. Multiple regression models were constructed with mean systolic and diastolic blood pressure, total cholesterol, HDL-cholesterol, plasma viscosity, and fibrinogen as dependent variables and $H$ pylori status as the independent variable with covariables age, sex, body mass index, smoking status, and exercise taken. Multiple logistic regression was performed with ischaemic heart disease as the dependent variable, $H$ pylori infection as the independent variable, and covariables age, sex, social class, smoking habit, and HDL-cholesterol.

\section{Results}

Of 2115 subjects (1047 men and 1068 women) with measured IgG antibodies to $H$ pylori, 1219 (57.6\%) were $H$ pylori positive and $135(6.4 \%)$ had ischaemic heart disease ( $82.5 \%$ aged 45 years or older). The male to female ratio of $H$ pylori positivity was $1: 1$ and that of ischaemic heart disease was $1.65: 1$.

The prevalence of serum antibodies to $H$ pylori increased with age and from social class I to $\mathrm{V}$ (table 1). Bivariable analysis of data from all participants showed that there were positive relations between infection with $H$ pylori and systolic and diastolic blood pressure, body mass index, plasma viscosity, and total cholesterol, and a negative relation with HDL-cholesterol (table 2). With adjustment for potential confounding variables (including age, sex, body mass index, smoking, and exercise) using multiple regression these relations were not statistically significant (table 3 ). $H$ pylori infection was more common in current smokers $(60 \cdot 1 \%)$ and ex-smokers $(63.8 \%)$ than in non-smokers $(52.6 \%)$ $\left(\chi^{3} 21.8 \mathrm{df} 3, \mathrm{P}<0.0001\right)$ and this relation 
Table 1 Age and social class distribution of participants infected with $H$ pylori

\begin{tabular}{llll}
\hline $\begin{array}{l}\text { Age group } \\
\text { (years) }\end{array}$ & $\begin{array}{l}\text { H pylori } \\
\text { positive (\%) }\end{array}$ & $\begin{array}{l}\text { Social } \\
\text { class }\end{array}$ & $\begin{array}{l}\text { H pylori } \\
\text { positive (\%) }\end{array}$ \\
\hline $25-29$ & $38 \cdot 5$ & & \\
$30-34$ & $37 \cdot 7$ & I & $38 \cdot 0$ \\
$35-39$ & $51 \cdot 1$ & II & $45 \cdot 3$ \\
$40-44$ & $56 \cdot 1$ & IINM & $52 \cdot 4$ \\
$45-49$ & $63 \cdot 3$ & IIIM & $66 \cdot 5$ \\
$50-54$ & $65 \cdot 6$ & IV & $70 \cdot 4$ \\
$55-59$ & $68 \cdot 5$ & V & $66 \cdot 0$ \\
$60-64$ & $72 \cdot 9$ & & \\
\hline
\end{tabular}

remained significant for those smoking 20 or more cigarettes a day (odds ratio of infection (95\% confidence interval (CI); $1.4(1.06$ to $1 \cdot 86), P=0.02)$ after adjustment for age, sex, and social class.

Analysis of data relating only to male participants produced similar results. When analysis was confined to female participants a weak but

Table 2 Bivariable analysis: cardiovascular risk factors and Helicobacter pylori (H pylori)infection

\begin{tabular}{lclccr}
\hline Variable & $\begin{array}{l}\text { Mean (SD) } \\
\text { H pylori negative }\end{array}$ & $\begin{array}{l}\text { Mean }(S D) \\
\text { H pylori positive }\end{array}$ & $\begin{array}{l}\text { Difference } \\
\text { in means }\end{array}$ & $\begin{array}{l}t \\
\text { statistic }\end{array}$ & PValue \\
\hline $\begin{array}{l}\text { Systolic blood } \\
\text { pressure (mm Hg) }\end{array}$ & $126(18)$ & $130(21)$ & 4 & 4.66 & $<0.001$ \\
$\begin{array}{l}\text { Diastolic blood } \\
\text { pressure }(\mathrm{mm} \mathrm{Hg})\end{array}$ & $76(12)$ & $78(12)$ & 2 & 3.15 & 0.002 \\
$\begin{array}{l}\text { Body mass index } \\
\left(\mathrm{kg} / \mathrm{m}^{2}\right)\end{array}$ & $25.2(4.0)$ & $25.9(4.3)$ & 0.7 & 3.87 & $<0.001$ \\
$\begin{array}{l}\text { Total cholesterol } \\
(\mathrm{mmol} / \mathrm{l})\end{array}$ & $5.91(1.18)$ & $6.12(1.26)$ & 0.21 & 3.98 & $<0.001$ \\
$\begin{array}{l}\text { HDL-cholesterol } \\
(\mathrm{mmol} / \mathrm{l})\end{array}$ & $1.36(0.35)$ & $1.3(0.34)$ & -0.06 & -3.59 & $<0.001$ \\
$\begin{array}{l}\text { Fibrinogen (g/l) } \\
\text { Plasma viscosity }\end{array}$ & $3.06(0.84)$ & $3.09(0.89)$ & 0.03 & 0.69 & 0.488 \\
$(\mathrm{cP})$ & $1.68(0.09)$ & $1.7(0.1)$ & 0.02 & 5.32 & $<0.001$ \\
\hline
\end{tabular}

Table 3 Multiple regression: cardiovascular risk factors as dependent variables, Helicobacter pylori (H pylori) infection as the independent variable with and without adjustment for potential confounders

\begin{tabular}{|c|c|c|c|}
\hline Variable & Adjusted for & $\begin{array}{l}\text { Difference in variable } \\
\text { mean }(S E) \text { between } \\
H \text { pylori positive } \\
\text { and H pylori negative } \\
\text { participants }\end{array}$ & PValue \\
\hline \multicolumn{4}{|l|}{ All participants } \\
\hline \multirow{3}{*}{$\begin{array}{l}\text { Mean systolic blood pressure } \\
\text { (mm HG) }\end{array}$} & - & $4 \cdot 16(0 \cdot 89)$ & $<0.001$ \\
\hline & Age & $-0.62(0.82)$ & 0.45 \\
\hline & Age and sex & $-0.78(0.81)$ & $0 \cdot 34$ \\
\hline \multirow{3}{*}{$\begin{array}{l}\text { Mean diastolic blood pressure } \\
(\mathrm{mm} \mathrm{Hg})\end{array}$} & & $1.72(0.55)$ & 0.002 \\
\hline & Age & $-0.22(0.54)$ & 0.69 \\
\hline & Age and sex & $-0.37(0.53)$ & 0.48 \\
\hline \multirow[t]{3}{*}{ Total cholesterol $(\mathrm{mmol} / \mathrm{l})$} & & $0.214(0.05)$ & $<0.001$ \\
\hline & Age & $-0.02(0.05)$ & $0 \cdot 71$ \\
\hline & $\begin{array}{l}\text { Age, sex, body mass } \\
\text { index, smoking, and } \\
\text { exercise }\end{array}$ & $-0.05(0.05)$ & $0 \cdot 31$ \\
\hline \multirow{3}{*}{ Body mass index $\left(\mathrm{kg} / \mathrm{m}^{2}\right)$} & - & $0.72(0.19)$ & $<0.001$ \\
\hline & Age & $-0.30(0.19)$ & $0 \cdot 11$ \\
\hline & $\begin{array}{l}\text { Age, sex, smoking, and } \\
\text { exercise }\end{array}$ & $-0.30(0 \cdot 19)$ & $0 \cdot 12$ \\
\hline \multirow[t]{3}{*}{ HDL cholesterol $(\mathrm{mmol} / \mathrm{l})$} & & $-0.06(0.02)$ & $<0.001$ \\
\hline & Age & $-0.05(0.02)$ & 0.002 \\
\hline & $\begin{array}{l}\text { Age, sex, body mass } \\
\text { index, smoking, and } \\
\text { exercise }\end{array}$ & $-0.03(0.01)$ & 0.06 \\
\hline \multirow[t]{3}{*}{ Fibrinogen $(g / 1)$} & - & $0.03(0.04)$ & $0 \cdot 488$ \\
\hline & Age & $-0.07(0.04)$ & 0.01 \\
\hline & $\begin{array}{l}\text { Age, sex, body mass } \\
\text { index smoking, and } \\
\text { exercise }\end{array}$ & $-0.09(0.04)$ & 0.02 \\
\hline \multirow{3}{*}{ Plasma viscosity $(\mathrm{cP})$} & - & $0.02(0.004)$ & $<0.001$ \\
\hline & Age & $0.01(0.004)$ & 0.02 \\
\hline & $\begin{array}{l}\text { Age, sex, body mass } \\
\text { index smoking, and } \\
\text { exercise }\end{array}$ & $0.01(0.004)$ & $0 \cdot 1$ \\
\hline \multicolumn{4}{|l|}{ Women } \\
\hline \multirow[t]{3}{*}{ HDL cholesterol $(\mathrm{mmol} / \mathrm{l})$} & - & $-0.08(0.02)$ & $<0.001$ \\
\hline & Age & $-0.07(0.02)$ & $<0.001$ \\
\hline & $\begin{array}{l}\text { Age, body mass index, } \\
\text { smoking and exercise }\end{array}$ & $-0.06(0.02)$ & 0.006 \\
\hline
\end{tabular}

significant negative relation between infection with $H$ pylori and HDL-cholesterol remained after adjustment for age, body mass index, smoking, and exercise (mean (SE) difference in HDL-cholesterol between $H$ pylori positive and $H$ pylori negative participants -0.06 $(0.02)(\mathrm{mmol} / \mathrm{l}), \mathrm{P}=0.006)$.

Bivariable analysis of data from all participants showed no significant difference between mean (SD) fibrinogen concentrations in $H$ pylori negative $(3.06(0.84) \mathrm{g} / \mathrm{l})$ and $H$ pylori positive individuals $(3.09(0.89) \mathrm{g} / \mathrm{l}$, independent samples $t$ test, $P=0.49$ ) but after adjustment for age, sex, body mass index, smoking, and exercise a weak, though significant, negative association between $H$ pylori infection and fibrinogen concentration was seen (mean (SE) difference in fibrinogen between $H$ pylori positive and $H$ pylori negative participants $-0.09(0.04, \quad P=0.02)$. This association held when only male participants were examined. A similar pattern was seen in female individuals, although the relation did not achieve statistical significance.

Table 4 gives the odds ratio for the association of infection with $H$ pylori and ischaemic heart disease before and after adjustment for potential confounding variables. Analysis of data from all participants before adjustment showed that the odds ratio for ischaemic heart disease was increased in patients infected with $H$ pylori (odds ratio ( $95 \% \mathrm{CI}) 2.38$ ( 1.59 to $3.56), \mathrm{P}<0.0001)$. The direction of this association held after adjustment for age, sex, social class, smoking habit, and HDL-cholesterol but the magnitude of the odds ratio decreased, and the association was no longer statistically significant (odds ratio (95\% CI) $1.51(0.93$ to 2.45$), P=0 \cdot 1)$. A similar pattern was seen when the analysis was restricted to only male or female subjects.

Table 5 gives the logistic regression model for all participants. Social class remained strongly and significantly associated with ischaemic heart disease after adjustment for age, sex, smoking habit, HDL cholesterol, and $H$ pylori infection (odds ratio, manual $v$ non-manual $(95 \% \mathrm{CI}) 1.97(1.26$ to 3.07$)$, $P=0.003)$. This association also remained after further adjustment for conventional cardiovascular risk factors of blood pressure, total cholesterol, body mass index, fibrinogen, and plasma viscosity (odds ratio, manual $v$ non-manual $(95 \% \mathrm{CI}) 1 \cdot 82(1 \cdot 14$ to $2 \cdot 91)$, $P=0.01)$.

\section{Discussion}

A case-control study ${ }^{8}$ has demonstrated an association between $H$ pylori infection and development of ischaemic heart disease, although the authors acknowledged deficiencies in their study design and recommended further investigation to confirm (or refute) the association. If $H$ pylori infection is a risk factor for the development of ischaemic heart disease then this risk factor may be highly modifiable. Effective treatment is available for $H$ pylori infection $^{17}$ and eradication regimens are becoming simpler and more acceptable. 
Table 4 Logistic regression: ischaemic heart disease as the dependent variable, Helicobacter pylori infection as the independent variable with and without adjustment for potential confounders

\begin{tabular}{lll}
\hline Adjusted for & $\begin{array}{l}\text { Odd ratio } \\
(95 \% \text { confidence interval) }\end{array}$ & $P$ Value \\
\hline All participants & & \\
$\overline{\text { Age }}$ & $2.38(1.59$ to 3.56$)$ & $<0.0001$ \\
Age and sex & $1.67(1.1$ to 2.52$)$ & 0.02 \\
Age, sex and social class & $1.63(1.08$ to 2.48$)$ & 0.02 \\
Age, sex, social class and smoking & $1.58(0.98$ to 2.55$)$ & 0.06 \\
Age, sex, social class, smoking and HDL & $1.55(0.96$ to 2.5$)$ & 0.07 \\
Men & $1.51(0.93$ to $2 \cdot 45)$ & 0.1 \\
Age & $2.86(1.65$ to 4.94$)$ & 0.0002 \\
Age and social class & $1.94(1.1$ to 3.41$)$ & 0.02 \\
Age, social class, and smoking & $1.68(0.90$ to 3.10$)$ & 0.1 \\
Age, social class, smoking and HDL & $1.62(0.87$ to 3.03$)$ & 0.12 \\
Women & $1.68(0.89$ to 3.16$)$ & 0.1 \\
Age & $1.78(0.97$ to 3.26$)$ & 0.06 \\
Age and social class & $1.32(0.71$ to 2.45$)$ & 0.38 \\
Age, social class and smoking & $1.49(0.69$ to 3.17$)$ & 0.31 \\
Age, social class, smoking and HDL & $1.53(0.71$ to 3.29$)$ & 0.27 \\
\hline
\end{tabular}

HDL, high density lipoprotein.

Table 5 Logistic regression model for all participants of ischaemic heart disease, $H$ pylori infection, and potential confounding variables

\begin{tabular}{llc}
\hline Variable & Odds ratio $(95 \%$ confidence interval) & $P$ Value \\
\hline H pylori infection & $1.51(0.93$ to 2.45$)$ & 0.1 \\
Age (years) & $1.07(1.05$ to 1.10$)$ & $<0.001$ \\
Sex (F:M) & $0.85(0.51$ to 1.40$)$ & 0.53 \\
Smoking & & \\
Ex-smoker & $1.64(0.96$ to 2.80$)$ & 0.07 \\
<20 cigarettes a day & $2.04(1.14$ to 3.66$)$ & 0.02 \\
> 20 cigarettes a day & $1.12(0.58$ to 2.19$)$ & 0.72 \\
HDL cholesterol (mmol/1) & $0.11(0.05$ to 0.24$)$ & $<0.001$ \\
Social class (NM:M) & $1.97(1.26$ to 3.07$)$ & 0.003 \\
\hline
\end{tabular}

Furthermore, reinfection after successful eradication in adulthood is not common and the eradicated state, once achieved, is prolonged ${ }^{18}$ and may be life long. Life time modification of a risk factor for ischaemic heart disease may, therefore, be possible after a short course of antibiotics and acid suppressive drugs. There can be little doubt that the elucidation of the nature of the relation between $H$ pylori infection and ischaemic heart disease is of major public health importance.

Examination of stored serum from participants recruited in Northern Ireland into the MONICA Project afforded an opportunity to examine, in a cross sectional population survey, the relation between $H$ pylori infection, cardiovascular risk factors and ischaemic heart disease. The response rate obtained in this survey $(65.2 \%$ of eligible and traceable individuals) may be lower than is desirable for a study of this nature and if non-responders differ significantly from responders in respect of a link between ischaemic heart disease and infection with $H$ pylori the magnitude (and possibly direction) of any association between these two variables may be affected. About $10 \%$ of the original sample were untraceable and it is possible that participants not traced may differ from those successfully traced either in their $H$ pylori or ischaemic heart disease status, for example the "well" or those from higher social classes (lower prevalence of $H$ pylori infection) may be more mobile. The age, sex, and social class structure of the study population, however, closely resembled that of
Northern Ireland as a whole. Serum was not available for analysis of antibodies to $H$ pylori from all participants but the lack of serum was random and unlikely to introduce any systematic error.

In this study no association was found between $H$ pylori infection and body mass index, blood pressure, total cholesterol, or plasma viscosity. A weak but significant association was shown between infection and HDLcholesterol in women and a similar pattern was seen in men which did not achieve statistical significance. The clinical significance of such a weak association is debatable.

We also found a weak negative association between $H$ pylori positivity and fibrinogen. This is in contrast to the finding by Patel et $a l^{10}$ of a strong positive association between $H$ pylori infection and fibrinogen despite both studies using similar assays. The study by Patel et al examined fibrinogen concentrations in only 72 men aged 50-69 years selected from a general practice, while this study examined concentrations in 2101 subjects, both men and women aged 25-64 randomly selected from the general population.

It would therefore seem that if $H$ pylori infection is associated with the development of ischaemic heart disease then this association is independent of conventional cardiovascular risk factors and that, in particular, the effect is not mediated through an increase in fibrinogen in infected persons.

The classification of angina pectoris in epidemiological studies is frequently made on the basis of the London School of Hygiene cardiovascular questionnaire-the Rose questionnaire ${ }^{19}$-as in this study. The validity of this instrument has been subject to considerable scrutiny and its sensitivity has been shown to range from 25 to $83 \%$ and specificity from 48 to $98 \%$. The reliability of the questionnaire for identifying myocardial ischaemia has been shown to be particularly low in females. ${ }^{20}$ Despite this the questionnaire is generally well regarded as a means of measuring angina pectoris in population based studies, although its use may result in some misclassification of ischaemic heart disease. Misclassification of outcome (ischaemic heart disease) is therefore a possibility in this study. Such misclassification will reduce the association between $H$ pylori infection and ischaemic heart disease unless $H$ pylori related dyspepsia is wrongly classified as cardiac pain of ischaemic origin. However, as current evidence does not support a significant association between $H$ pylori infection and non-ulcer dyspepsia and as most dyspepsia is not ulcer related (and therefore not $H$ pylori related) any misclassification of dyspepsia as ischaemic heart disease is, in fact, unlikely to increase the odds ratio of the association. Furthermore, the extent of misclassification of dyspepsia as ischaemic heart disease may be small: the proportions of participants taking antacids in the 2 weeks before interview were similar in those with ischaemic heart disease or without $(7 \cdot 0 \%$ and $6.6 \%$ respectively).

Misclassification of exposure is possible if $H$ pylori infection does not precede the develop- 
ment of ischaemic heart disease in all cases. Acquisition of $H$ pylori infection in adulthood is rare, ${ }^{2122}$ however, infection predominantly occurring in childhood and therefore likely to precede ischaemic heart disease.

In this study the odds ratio for ischaemic heart disease was increased in patients infected with $H$ pylori before and after adjustment for the confounding effects of age, sex, social class, smoking habit, and HDL-cholesterol. Other cardiovascular risk factors were not included in the logistic regression model as they were not associated with $H$ pylori infection and therefore were not, by definition, confounding variables. Although the association of fibrinogen with ischaemic heart disease is well established and in our study fibrinogen is negatively associated with $H$ pylori infection and is therefore a potential confounder, it has not been included in the logistic regression model as other investigators have suggested that it may lie on the causal pathway. ${ }^{10}$ The association between infection and ischaemic heart disease did not achieve conventional statistical significance on controlling for confounding variables but the magnitude of the effect and the small decrease in odds ratios with further adjustment after correction for age support a potentially important association.

The data in this study may, therefore, suggest an important association between $H$ pylori infection and ischaemic heart disease but as infection is closely related to deprivation in childhood $H$ pylori may merely be a proxy measure for some aspect of childhood deprivation which exerts an effect on the development of ischaemic heart disease in later life. We were unable to examine the effect of controlling for childhood living circumstances as no such data were collected.

Social class was associated with ischaemic heart disease independently of established cardiovascular risk factors and controlling for $H$ pylori infection had minimal effect on the association. Despite infection with $H$ pylori being closely associated with social class and infection possibly being an independent risk factor for ischaemic heart disease there was no evidence to suggest that the social class inequality in ischaemic heart disease can be attributed to infection with this organism.

In conclusion, this study suggests that $H$ pylori may be independently associated with the development of ischaemic heart disease but if this is so the mechanism by which this effect is exerted is not through infection increasing plasma fibrinogen. Furthermore, $H$ pylori infection does not explain the social class inequality in ischaemic heart disease which exists independently of known cardiovascular risk factors. Further investigation, for example prospective cohort studies with assessment of childhood living conditions or intervention studies, are required to elucidate more clearly the relation between $H$ pylori and ischaemic heart disease.

We thank Dr E Maine, Mr T Ingles, and the staff of the Blood Bank of the Royal Victoria Hospital, Belfast for estimation of fibrinogen concentrations plasma viscosity, Dr D McMaster, Department of Medicine, Queen's University of Belfast for processing and storing blood samples, Mr B O'Loughlin, Department of Microbiology, Queen's University of Belfast for advice and technical support, and Dr C Patterson, Department of Epidemiology and Public Health, Queen's University of Belfast for statistical advice. LJM was supported by a Department of Health and Social Services research fellowship.

1 Pocock SJ, Shaper AG, Cook DG, Phillips AN, Walker M. Social class differences in ischaemic heart disease in British men. Lancet 1987;ii: 197-201.

2 Rose G, Marmot MG. Social class and coronary heart disease. Br Heart f 1981;45:13-9.

3 Suadicani P, Hein HO, Gyntelberg F. Are social inequalities associated with the risk of ischaemic heart disease a tesult of psycholo thal working conditions. Atherosclerosis 1993;10:1165-75.

4 Sitas F, Forman D, Yarnell JWG, et al. Helicobacter pylori infection rates in relation to age and social class in a population of Welsh men. Gut 1991;32:25-8.

5 Whitaker CJ, Dubiel AJ, Galpin OP. Social and geographical risk factors in Helicobacter pylori infection. Epidemiol Infect 1993;111:63-70.

6 Graham DY, Malaty HM, Evans GE, Evans DJ, Klein PD, Adam E. Epidemiology of Helicobacter pylori in an asymptomatic population in the United States. Gastroenterology 1991;100:1495-501.

7 Fiedorek SC, Malaty HM, Evans DL, et al. Factors influencing the epidemiology of Helicobacter pylori infection in encing the epidemiology of Helicobacter
children. Pediatrics 1991;88:578-82.

8 Mendall MA, Goggin PM, Molineaux N, et al. Relation of Helicobacter pylori and coronary heart disease. Br Heart $\mathcal{f}$ 1994;71:437-9.

9 Yarnell JW, Baker IA, Sweetnam PM, et al. Fibrinogen, viscosity, and white blood cell count are major risk factors for ischemic heart disease. Circulation 1991;83: 836-44.

10 Patel P, Carrington D, Strachan DP, et al. Fibrinogen: a link between chronic infection and coronary heart disease. Lancet 1994;343:1634-5.

11 Markowe HJL, Marmot MG, Shipley MJ, et al. Fibrinogen: a possible link between social class and coronary heart disease. $B r M$ F 1985;291:1312-4.

12 Baker IA, Sweetnam PM, Yarnell JWG, Bainton D, Elwood PC. Haemostatic and other risk factors for ischemic heart disease and social class: evidence from the Caerphilly and Speedwell Studies. Int $\mathcal{f}$ Epidemiol 1988; 17:759-65.

13 Evans AE, Kerr MMcF, McCrum EE, et al. Coronary risk factor prevalence in a high incidence area: results from the Belfast Monica Project. Ulster Med F 1989;58:60-68.

14 Lopes-Virella MF, Stone P, Ellis S. Cholesterol determination in high-density lipoproteins separated by three different methods. Clin Chem 1977;23:882-4.

15 Harkness J. The viscosity of human blood plasma: its measurement in health and disease. Biorheology 1971;8: 171-93.

16 Stacey AR, Hawtin PR, Newell DG. Antigencity of fractions of Helicobacter pylori prepared by fast protein liquid chromatography and urease captured by monoclonal antibodies. Eur F Clin Microbiol Infect Dis 1990;9:732-7.

17 Chiba N, Rao BV, Rademaker JW, Hunt RH. Meta-analysis of the efficacy of antibiotic therapy in eradicating Helicobacter pylori. Am 7 Gastroenterol 1992;87:1716-27.

18 Forbes GM, Glaser ME, Cullen DJE, et al. Duodenal ulcer treated with Helicobacter pylori eradication: seven year follow-up. Lancet 1994;343:258-60.

19 Rose GA. The diagnosis of ischaemic heart pain and intermittent claudication in field surveys. Bull World Health Organ 1962;27:645-58.

20 Garber CE, Carleton RA, Heller GV. Comparison of "Rose questionnaire angina" to exercise thallium scintigraphy: different findings in males and females. $f$ Clin Epidemiol 1992;45:715-20.

21 Parsonnet J, Blaser MJ, Perez-Perez GI, Hargrett-Bean N, Tauxe RV. Symptoms and risk factors of Helicobacter pylori infection in a cohort of epidemiologists. pylori infection in a cohor

22 Cullen DJE, Collins BJ, Christiansen KJ, et al. When is Helicobacter pylori infection acquired? Gut 1993;34: 1681-2. 